\title{
Algunas reflexiones sobre la guerra en Iraq
}

ROODY RÉSERVE

\author{
¿Quién creerá en la justicia de vuestra guerra, \\ si la libran sin mesura? \\ FRANÇOIS DE LA NOUE
}

\section{Argumentos encontrados sobre la guerra de Iraq}

La guerra que los gobiernos del estadounidense George W. Bush y del británico Tony Blair desataron contra Iraq, terminó ya hace un par de meses. Se sabe que murieron poco menos que un centenar de soldados de la coalición. De las muertes civiles y militares iraquíes no se tiene noticias. Los líderes de los países que se opusieron a la guerra anglonorteamericana ya se reconciliaron con Bush. El consejo de Seguridad de las Naciones Unidas ya legalizó la guerra ${ }^{1}$. El secretario del organismo mundial nombró su representante para Iraq, el brasileño Sergio Vieira de $\mathrm{Mello}^{2}$. Bush cumplió los designios de su antecesor, Bill Clinton, que había prometido trabajar con la diplomacia siempre y cuando era posible y que ello redundaba en beneficio de los intereses de su país. ${ }^{3}$ Sin embargo, pese al carácter de hecho consumado que los que toman decisiones en la política mundial se esfuerzan en dar de la acción unilateral de la coalición en Iraq, sigue vigente la pregunta de por qué había que atacar a este país. 
La coalición dio varios motivos para sustentar el ataque. En el discurso de la noche del inicio de las hostilidades declaró Bush: «nuestra misión es clara - desarmar a Iraq de armas de destrucción masiva, para terminar con el apoyo de Saddam Hussein al terrorismo, y para liberar al pueblo Iraquí. Primero, hay quienes preguntan por qué es diferente Iraq de otros países o regímenes que también tienen armas terribles. Aunque existen muchos peligros en el mundo, la amenaza sobresale porque reúne en un lugar los peligros más serios de nuestra era. Las armas de destrucción en masa de Iraq son controladas por un tirano asesino que ya ha utilizado armas químicas para matar a miles de personas. Este mismo tirano ha tratado de dominar el Medio Oriente, ha invadido y ocupado un vecino pequeño, ha atacado a otras naciones sin advertencia y siente una hostilidad implacable hacia los Estados Unidos. Debido a sus actos pasados y presentes, debido a su capacidad tecnológica, debido a la naturaleza inmisericorde de su régimen, Iraq es único. Como ha dicho un antiguo inspector en jefe de armas de la $\mathrm{ONU}$, «El problema fundamental con Iraq sigue siendo la naturaleza del propio régimen. Saddam Hussein es un dictador homicida que es adicto a las armas de destrucción en masa»» ${ }^{4}$.

Ahora bien, si uno de los motivos de la guerra fue el desarme de Iraq, dos meses después de la pomposa ceremonia de fin de conflicto que organizó el presidente Bush a bordo de un porta aviones en el pacífico, el pasado primero de mayo, no se han encontrado estas armas $^{5}$. La chispa que encendió la mecha fueron unas declaraciones de Donald Rumsfeld, secretario estadounidense de Defensa, que asumió públicamente la posibilidad de que las autoridades iraquíes hayan destruido sus armas antes de que empezara el conflicto armado. En otros términos, el argumento principal esgrimido para sostener la invasión anglonorteamericana a Iraq desapreció de súbito. En claro, dos meses después del fin de la guerra, no hay indicio alguno acerca de la presencia de las armas de exterminio masivo y, al parecer, los beligerantes lo sabían de antemano. La idea de una campaña de engaño sabiamente organizada por los partidarios de la guerra en Washington y en Londres se hace cada día más fuerte ${ }^{6}$. Tanto los legisladores que votaron por la guerra ante la supuesta inminencia de un ataque de Sadam Hussein como los ciudadanos de los países que apoyaron la solución armada habrían sido timados por sus gobernantes. Tal idea cobró más fuerza luego de la declaración de Paul Wolfowitz, un alto funcionario 
del gabinete de Rumsfeld, según la cual el trato que el gobierno de Bush dio a las informaciones relativas a las supuestas armas de destrucción masiva en Iraq obedeció más a un afán de convencer a la opinión pública más que al convencimiento de la existencia real de estas armas.

Tanto en los Estados Unidos como en Gran Bretaña, las noticias sobre un eventual engaño de los hombres del poder a sus parlamentarios y a la opinión pública amenazó con tornarse en una viva polémica. Blair tuvo que anunciar el nombramiento de una comisión de investigación sobre el tema. En los Estados Unidos, el senado decidió iniciar una investigación para dirimir el papel de los servicios secretos en la información sobre las supuestas armas de destrucción masiva de Iraq, mientras que sigue en entredicho el papel de la Agencia de Inteligencia (CIA) en el caso. En todo caso, independientemente del resultado final de las pesquisas, no cabe duda de que, mientras que sectores independientes no pongan manos sobre las presuntas armas de destrucción masiva con que supuestamente amenazaba el régimen de Hussein, la suspicacia perseguirá a los mandatarios Bush y Blair sobre sus reales motivos para iniciar la guerra en Iraq.

Los argumentos acerca de la crueldad del régimen de Sadam Hussein que hoy en día esgrimen los defensores de la invasión de la «coalición» en Iraq, tampoco son suficientes para dar legitimidad a una decisión ilegal, que dejó en entredicho el sistema internacional de resolución de los conflictos. Las naciones Unidas fueron dejadas de lado por la administración de Bush que ratificó su vocación hacia el unilateralismo ${ }^{7}$ reivindicado desde el principio por su gobierno. Por muy sanguinario que pudo haber sido el régimen de Sadam Hussein, la ley internacional no reconoce ninguna posibilidad de emprender una guerra en nombre de las Naciones Unidas para deponer a un presidente de otro país. Mucho menos si se trata de una guerra sospechosa, cuyo objetivo final, perciben algunos, se encuentra en un deseo de control imperial sobre una parte conflictiva y de gran importancia económica para el mundo ${ }^{8}$.

En cuanto a los lazos supuestos del régimen iraquí con los terroristas de $\mathrm{Al}$ Qaeda, tampoco se han presentado documentos algunos que permitan afirmar sin ambages tales relaciones. El informe de Colin Powell, secretario de los estados unidos, el 4 de febrero de 2003, no 
despejó las dudas de los más escépticos. El primer ministro Francés, Dominique de Villepin, declaró el 14 del mismo a unos periodistas: «Hace diez días, Powell evocó supuestos vínculos entre Al Qaeda y el régimen de Bagdad. En el estado actual de nuestras investigaciones e informaciones llevadas a cabo junto con nuestros aliados, nada nos permite establecer esos vínculos". Y, lo mismo ha resultado al final de la guerra. No se han podido demostrar las supuestas relaciones entre el régimen de Bagdad y los temibles terroristas de la nebulosa red terrorista de $\mathrm{Al}$ Qaeda.

\section{Las Naciones Unidas en la tormenta después de la guerra}

La férrea oposición de Francia, Rusia y Alemania, entre otros, en el seno del Consejo de Seguridad de la ONU, a los planes de guerra de Bush en Iraq dio pie a un serio cuestionamiento del balance de poder en el seno del Consejo de Seguridad y, de manera más general, sobre el nuevo papel de las Naciones Unidas en el mundo actual. Si después del fin de la guerra fría, el sistema de las Naciones Unidas se vio legitimado por una serie de tareas delegada a su responsabilidad por los diferentes países del mundo, la decisión de Bush de hacer la guerra sin tomar en cuenta la opinión de la entidad multilateral pone en entredicho este papel. Las Naciones Unidas son reducidas a un papel de apéndice de los Estados Unidos, encargadas de secundar los asuntos resueltos por este país.

La falta de prueba que respalden las acusaciones de Bush y de su aliado Blair ha contribuido a aumentar la indignación de quienes creen que se ha violado la carta de las Naciones Unidas y sus declaraciones de principio acerca de la necesidad de actuar conjuntamente para preservar a la humanidad del flagelo de la guerra9. La sensación generalizada de los observadores del desempeño de la ONU es que el organismo internacional ha fallado con su misión de defender la paz internacional e impedir la agresión bélica por parte de sus miembros. Si bien que no es la primera vez, desde la firma del documento, que un estado miembro hace efectivo un acto de agresión, la importancia de los Estados Unidos en el mundo y la manera en que decidió ignorar el Consejo de Seguridad contribuyó a caldear más el ambiente y aumentar la sensación de peligro que invade el mundo.

La ley internacional que regula las acciones de los miembros de la ONU en casos como el litigio de las Naciones Unidas con Iraq fue 
totalmente burlada. Los reiterados discursos en torno al derecho de la guerra preventiva ${ }^{10}$, no son suficientes para legalizar la acción de las fuerzas anglonorteamericanas. En efecto, pese a la controversia acerca del límite del artículo 51 de la carta de las Naciones Unidas que estipula el derecho a la legítima defensa ${ }^{11}$, el gobierno del presidente Bush no se basó en este argumento para respaldar en el seno del Consejo de Seguridad su disposición para atacar a Iraq. En cambio, el ataque a Afganistán, sede reconocida de la organización terrorista de Osama Bin Laden, Al Qaeda. fue avalado sin ambages por la ONU, por considerarse un caso de legítima defensa.

De ahí que para muchos observadores -entre ellos políticos, académicos y activistas de los derechos humanos-, la guerra llevada a cabo por las fuerzas angloestadounidenses en Iraq es de naturaleza de socavar las bases de acción de las Naciones Unidas. El gobierno de Bush y su aliado británico decidieron hacer a un lado el aviso de la mayoría de los miembros del Consejo de Seguridad de las Naciones Unidas. Lo cual hace de esta intervención armada una acción ilegal. Si bien que en sus 58 años de existencia las Naciones Unidas han vivido muchos momentos difíciles ${ }^{12}$, se piensa que esta última situación es de naturaleza para comprometer su legitimidad y eficacia. El contexto post 11 de septiembre y la nueva doctrina de política internacional del mandatario estadounidense están llamados a minar la base de crédito del organismo multilateral.

En fin, se podría sostener que los acontecimientos en torno a la guerra permiten llegar a una conclusiones sobre el funcionamiento de la ONU 1) la ONU no tiene relevancia en el manejo de la política internacional 2) hay una creciente conciencia internacional de la dependencia y falta de prestigio del organismo internacional 3) hay una necesidad insoslayable de reestructuración de la ONU. Si bien que el secretario general del organismo multilateral, Kofi Annan, ha recalcado el papel humanitario importante del organismo en este contexto de reconstrucción de Iraq y en la resolución de otros conflictos como el de Corea del Norte, no cabe duda que sufre de un fuerte crisis de legitimidad. De ahí que el enfoque multilateralista de abordaje de los problemas internacionales se encuentra seriamente cuestionado. 


\section{3. ¿Es posible el multilateralismo?}

La manera en que los Estados Unidos condujeron el forcejeo con la ONU sobre el papel que los demás países deberían de jugar en su decisión de atacar a Iraq, dio pie a la discusión sobre el multilateralismo. Éste término, que evoca la voluntad de los estados de enfrentar los problemas que afectan el mundo desde la concurrencia de un conjunto de estados, se encuentra fuertemente cuestionado. Tal manera de enfrentar los problemas mundiales, asegura la seguridad de todos y evita los problemas de guerra repetida entre los diferentes estados. $\mathrm{La}$ creación de las Naciones Unidas, después del fin de la segunda guerra mundial, ha sido la manifestación más patente de esta voluntad multilateral de los pueblos para enfrentar los problemas del mundo ${ }^{13}$. Durante los largos 45 años que duró la guerra fría, el multilateralismo en las Naciones Unidas se vio bastante afectado. Sin embargo, el derrumbe del bloque soviético caracterizado por el enfrentamiento entre el este comunista liderado por la Unión Soviética, y los Estados Unidos, el mentor de las potencias del «mundo libre», dio un nuevo brillo a la organización mundial. Si bien que siguió siendo un lugar de discusión y armonización de los intereses de las grandes potencias en las diferentes regiones del mundo, no cabe duda que la ONU adquirió un papel relevante en la solución de importantes conflictos en el mundo ${ }^{14}$.

Ahora bien, a raíz de los acontecimientos de los últimos meses en el seno del Consejo de Seguridad, se empieza a debatir las limitaciones del multilateral de soluciones de los problemas internacionales. En fin, el principio multilateral de enfrentamiento de los problemas parece estar en contradicción con la idea que tiene América de lo que tiene que ser el mundo. La «Idea de América» nació como una consciente vocación de los Estados Unidos para ser diferente y exportar su civilización a los demás pueblos del mundo. Ya en el siglo 19, el décimo octavo presidente de los Estados Unidos Ulysses Grant, en su segundo discurso de toma de posesión, en 1872, lo expresó de esta forma: "Tengo la firme convicción de que el mundo civilizado se inclina hacia el republicanismo y que nuestra gran República está destinada a ser la estrella que guíe a las demás... Creo que el Hacedor está preparando al mundo para que, llegado el momento, se transforme en una gran nación que siga nuestros pasos» ${ }^{15}$. 
Es de constatar que no sólo la idea de una América superior y dispuesta a liderar el resto de las naciones ha sobrevivido hasta nuestros días, sino que también el actual mandatario de los Estados Unidos ha manifestado su deseo de poner su poderío militar al servicio de esta causa, en un contexto internacional hostil que amenaza sus intereses particulares y la vida de sus habitantes. «Nuestra victoria en Iraq será un avance crucial en la guerra contra el terrorismo, pero la lucha continúa... desde el día que nuestro país fue atacado (el 11 de septiembre de 2001), hemos enviado un mensaje claro a todos los que nos amenazan, a nuestros amigos y aliados: Los Estados Unidos de América y nuestra coalición nos defenderemos. Cuando hicimos el juramento nos comprometimos, sostendremos nuestra palabra y lo que empezamos lo terminaremos. Este gobierno esta actuando para proteger al pueblo estadounidense de las amenazas de una nueva era» ${ }^{16}$. manifestó Bush.

Pero, es de notar que esta idea del papel de América en el mundo, por un lado despierta la animosidad de muchos países y, por otro, choca con la concepción multilateralista de solución de los problemas del mundo. Aunque, a decir verdad, en su documento sobre la Seguridad Nacional de los Estados Unidos, el equipo de Bush hace algunas concesiones hacia el multilateralismo: Si bien nuestro principal objetivo es defender a los Estados Unidos, sabemos que para derrotar al terrorismo en el mundo unificado de hoy necesitamos el apoyo de nuestros aliados y amigos. Siempre que sea posible, Estados Unidos dependerá de organismos regionales y poderes estatales para que cumplan sus obligaciones de luchar contra el terrorismo. Cuando un gobierno encuentre que la lucha en contra del terrorismo está por encima de sus medios, compensaremos su voluntad y sus recursos con cualquier tipo de ayuda que nosotros y nuestros aliados podamos ofrecer» ${ }^{17}$.

\section{Si vis pacem..., La nueva Estrategia de Seguridad Nacional de Bush}

Este viejo adagio griego, en opinión de muchos, resume con bastante exactitud la nueva doctrina del presidente de los Estados Unidos George W. Bush. Se sostiene que ya el día siguiente del ataque del 11 de septiembre Donald Rumsfel, secretario de Defensa norteamericano, habría propuesto la invasión de Iraq como una forma efectiva de ir 
lavando la afrenta y, especialmente, disuadir a aquellos que hubieran pensado en manifestar hostilidades en el futuro hacia los Estados Unidos. Al mismo tiempo, los halcones que rodean al actual mandatario, están propugnando un despliegue de capacidad militar abrumadora, capaz de disuadir a cualquier temerario.

Algunos observadores destacan esta actitud en el documento sobre la Estrategia de Seguridad Nacional, publicado por la Casa Blanca el 20 de septiembre de 2002. Este texto, entre otros elementos, contiene cuatro referencias fundamentales que motivan las reflexiones más pesimistas de algunos observadores. Son cuatro temas neurálgicos en el documento sobre la Estrategia de Seguridad Nacional de Bush los que más han despertado la crítica de los observadores. En primer lugar, el documento hace la la acción militar preventiva en contra de estados y supuestos grupos terroristas que intentarían elaborar armas de destrucción masiva, un objetivo primordial de los Estados Unidos. En segundo lugar, el documento sobre la Estrategia de Seguridad Nacional declara inadmisible que una potencia extranjera rivalice el poderío de los Estados Unidos en el mundo. En tercer lugar, la Estrategia de Seguridad Nacional manifesta un nivel de compromiso multilateral de los Estados Unidos, bajo condiciones claramente inaceptables para el resto de las naciones. Si bien expresa su compromiso con la cooperación multilateral internacional, afirma claramente que «no dudaremos en actuar solos, en caso necesario" para defender los intereses y la seguridad nacionales. En cuarto lugar, el documento de la administración Bush sobre su Estrategia de Seguridad Nacional hace de la extensión de la democracia, de la promoción de los derechos humanos en todo el mundo uno de sus objetivos prioritarios.

El presupuesto militar de los Estados Unidos es superior o igual al presupuesto reunidos todos los demás países del mundo. Por eso, en su estrategia de seguridad nacional, el presidente George Bush, no tiene complejo en asumir esta realidad. «Hoy, Estados Unidos disfruta de una posición de fuerza militar sin paralelo y de gran influencia económica y política. De acuerdo con nuestro pasado y nuestros principios, no utilizamos nuestra fuerza para obtener ventajas unilaterales. En cambio, buscamos crear un equilibrio de fuerzas que favorezca la libertad humana». Pero, muchos otros países, especialmente los que no comparten las ideas estadounidenses sobre la organización de la economía y de la política, se sienten a merced de cualquier decisión 
caprichosa por parte de las autoridades de este país. Las declaraciones del presidente Bush sobre los regímenes de Siria, Cuba, Irán y Corea del Norte, por ejemplo, son dignos ejemplos del miedo y desazón que embargan a buena parte de la comunidad internacional. El miedo es que los Estados Unidos se conviertan en una policía del mundo que actúe para deponer a los gobiernos con que no simpatizan sus dirigentes ${ }^{18}$.

La idea de celebrar ataques preventivos contra los grupos terroristas o estados considerados parias por el gobierno de Washington amenaza con dar al traste con todo lo que se ha construido hasta ahora en términos de legalidad internacional. Hacer de ataques preventivos una estrategia de prevención en la lucha contra el terrorismo además, vuelve más inseguro el mundo y pone a todos los enemigos (o los considerados como tales por los decisores políticos en Washington) en una situación de clara desventaja. George W. Bush, sin embargo, cree que el momento histórico no demanda menos rigos. «Y, como una cuestión de sentido común y autodefensa, Estados Unidos actuará contra esas amenazas en surgimiento antes de que éstas terminen de formarse. No podemos defender a Norteamérica y a nuestros aliados esperando que todo salga bien. Por lo tanto, debemos estar preparados para frustrar los planes de nuestros enemigos, al utilizar la inteligencia y al proceder con deliberación. La historia juzgará severamente a aquellos que vieron venir este peligro y no actuaron. En el nuevo mundo en el que hemos entrado, el único camino hacia la paz y la seguridad es el de la acción» ${ }^{19}$.

En segundo lugar, para asegurarse de que nadie se oponga efectivamente a los «nobles» designios de su país, Bush se compromete a evitar el surgimiento de cualquier competidor embarazoso. «Nuestras fuerzas serán lo bastante potentes como para disuadir adversarios potenciales de emprender una acumulación de fuerzas militares con la esperanza de sobrepasar o igualar el poderío de Estados Unidos ${ }^{20}$. En claro, los Estados Unidos harán todo lo posible para seguir siendo los señores del mundo. No sólo no habrá lugar para países que desafíen las directivas estadounidenses, sino también es posible que tal postura se interprete como una amenaza para los intereses estadounidenses y un obstáculo para la consecución del objetivo de lucha eficaz contra el terrorismo. 
Por otro lado, los Estados Unidos están dispuestos a promover una nueva forma de multilateralismo. «Nos guía también la convicción de que ninguna nación puede por sí sola crear un mundo mejor, más seguro. Las alianzas y las instituciones multilaterales pueden multiplicar la fuerza de las naciones amantes de la libertad. Estados Unidos está comprometido con instituciones perdurables como las Naciones Unidas, la Organización Mundial del Comercio, la Organización de los Estados Americanos, la OTAN, así como otras alianzas de larga data. Las coaliciones de naciones dispuestas a participar pueden aumentar estas instituciones permanentes. En todos los casos, deben tomarse en serio las obligaciones internacionales. No se las debe tomar simbólicamente con el fin de obtener apoyo para un ideal, sin promover su realización $»^{21}$.

Esas declaraciones de buena intención despiertan en seguida la suspicacia cuando a renglón seguido el presidente norteamericano aclara su principal objetivo al hablar de multilateralismo. «Estados Unidos - dice Bush- tratará constantemente de obtener el apoyo de la comunidad internacional, no dudaremos en actuar solos». De ahí que se ha interpretado la opción multilateral de Bush en su verdadera dimensión. El presidente americano se siente legitimado por los valores que sostentan la tradición de su país, la importancia de la lucha que libra, para, incluso, actuar sin el respaldo de los demás países. Además, considera que la historia ha corroborado la justeza de la causa de su país.

Finalmente, Estados Unidos se compromete a extender la democracia a todas las regiones del mundo. Bush sigue creyendo, al igual que lo formularon sus antepasados, que la paz pasa por la democracia, la justicia y el fin de las tiranias. Estados Unidos debe defender la libertad y la justicia porque estos principios son justos y verdaderos para los pueblos de todas partes» ${ }^{22}$. Bush está convencio que el hecho de promover estos ideales redundarán en beneficio para la humanidad entera y para los demás pueblos del mundo. De esta manera, la promoción de la democracia en el mundo es parte integrante de la lucha en contra del terrorismo y de la estrategia de seguridad nacional de este país. Por lo que será necesario trabajar «activamente para llevar la esperanza de democracia, desarrollo, mercados libres y libre comercio a todos los rincones del mundo» ${ }^{23}$. 
Sin embargo, muchos han notado la gran diferencia que separa las proclamas de democracia, respeto a la dignidad humana etc. de los documentos que publica el equipo de Bush y su acción en el teatro de las operaciones. Es el caso, por ejemplo, de la situación de los prisioneros talibanes detenidos en la base de Guantánamo, fuera de toda consideración por la ley internacional. En la misma línea se encuentran las proclamas por la democracia y la libertad, mientras se siguen apoyando regímenes que no comulgan con estos principios. Siendo los líderes estadounidenses a la vez jueces y ejecutores de los principios proclamados y su realización en el terreno, no hay manera de asegurar una crítica efectiva de sus decisiones.

\section{Conclusiones}

Las reflexiones en torno al comportamiento de los Estados en el mundo, especialmente a raíz de los acontecimientos en a la invasión a Iraq, demuestra la complejidad del mundo en el que se desarrollan las relaciones internacionales actuales. Si bien que nadie puede dudar de la importancia de los Estados Unidos para el sistema internacional, es evidente que la creciente discreción que se atribuyen sus dirigentes en el abordaje de asuntos que conciernen otras naciones será objeto de disputas interminables. Ante los hechos consumados que el gobierno de la nación más poderosa del mundo no tienen complejos en hacer avalar a las Naciones Unidas, se vuelve más crucial la pregunta por el papel de este organismo en el mundo actual.

El papel activo que está llamado a asumir Estados Unidos en el mundo, especialmente en la coyuntura actual, plantea serios retos para el multilateralis $\mathrm{mo}^{24}$. Tal principio implica, por un lado el convencimiento de todos los actores implicados de que esa es la vía de solución de los problemas del mundo. Si bien que en esta materia, Estados Unidos se ha declarado partidario de esta opción, pero, como se ha visto, se reserva siempre el derecho de actuar solo cuando los demás estados no están dispuestos a seguir sus pasos. Esta última consideración, pone en entredicho el término mismo, porque no sólo hace la falta que los estados se declaren partidarios de la opción multilateral, tendría que existir un mecanismo de cohesión en caso de que un Estado decidiera pasar por encima de la voluntad de la mayoría o de ignorar las leyes internacionales. 
Y es precisamente en este punto en que se debilitan los organismos multilaterales frente a Washington. No existe fuerza militar y política en el mundo capaz de resistir las presiones militares o políticas de los Estados Unidos. En esa línea, siempre que el multilateralismo se encuentra en posición de obstaculizar los intereses o decisiones de los Estados Unidos, es evidente que confrontará un serio problema de credibilidad. La guerra de la coalición en contra de Iraq ha demostrado con bastante aplomo este hecho. Los Estados Unidos estaban convencidos de que había que derrocar el régimen de Sadam Hussein, no quedó más remedio, a pesar de las numerosas manifestaciones contrarias o de la oposición de la mayoría de los miembros del Consejo de Seguridad, de aceptar lo dictaminado por este país.

La sumisión a sus designios que exige la administración Bush no implica solamente la observación pasiva de las decisiones que toma en el mundo. El presidente norteamericano presiona y amenaza de represalias comerciales a los países contrarios a su decisión. A decir verdad, el gobierno de Bush no ha sido el primer norteamericano que ha manifestado su designio de defender la causa de su país sin tomar en cuenta el aviso e ideas de otras naciones. Como se ha visto, páginas más arriba en la exposición sobre la Idea de América, este país se caracteriza por que sus gobernantes asumen sin complejos que son la luz y el faro del mundo ${ }^{25}$. Que lo hagan con un lenguaje más o menos diplomático es un asunto que tiene que ver con el momento histórico determinado. En el fondo, todos se han consideran los llamados a liderar la humanidad y mostrarle el camino hacia la felicidad y la realización plena.

En fin, la discusión acerca del comportamiento de las naciones más poderosas en la Arena internacional reviva la discusión, hasta ahora irresuelta en la disciplina de las relaciones internacionales acerca del papel que desempeña el poder en la relación entre las naciones. Al respecto, decía Hans Morgenthau, «la esencia de la política internacional es idéntica a la de la política interna. Política interna y política internacional son, ambas, una lucha por el poder, modificada únicamente por las distintas circunstancias en que tiene lugar esta lucha por el poder en la esfera interna y en la esfera internacional» ${ }^{26}$. ¿se podrá compaginar las ambiciones de poder de los Estados Unidos con las de las demás naciones del mundo? ¿Es posible cambiar la lógica de la lucha por el poder, por una lógica de cooperación y de relación armo-

\section{2}

Realidad 93, 2003 
niosa entre los pueblos? Estas son algunas de las preguntas a las que el sistema internacional de nuestros días tendrá que enfrentar.

\section{Notas}

1. El Consejo de Seguridad de las Naciones Unidas aprobó con 14 votos la resolución que avala la invasión anglonorteamericana a Iraq. Legitima la presencia de las fuerzas ocupantes y acepta su rol secundario en este país.

2. En nombre del pragmatismo en política internacional el ministro de relaciones exteriores de Francia olvidó rápidamente su oposición a Washington: «Avec la chute du régime de Saddam Hussein, c'est une page sombre qui se tourne et nous nous en réjouissons", "Nous sommes à un moment décisif de l'histoire de l'Iraq et je veux croire à une nouvelle histoire pour le peuple Iraqien, avec la fin de la dictature», «Ensemble, il faut maintenant construire la paix en Iraq et cela passe pour la France par un rôle central des Nations unies «Je pense aussi aux peuples arabes, à leur inquiétude et à leur sentiment, souvent mêlé, de frustration, d'injustice et d'humiliation». Además, por otro lado, defendió su nueva postura frente al proyecto de resolución de la Administración Bush, luego de su triunfante campaña militar en Iraq, con una frase elocuente sobre la capitulación: «La priorité absolue de la France est de regarder vers son avenir»

3. Durante su discurso de toma de poder Cinton declaró lo siguiente: «Actuaremos cuando se produzca un desafío a nuestros intereses vitales, o a la voluntad y conciencia de la comunidad internacional: con la diplomacia pacífica cuando sea posible, con la fuerza cuando sea necesario». (ver Discurso de toma de posesión del presidente de los Estados Unidos, Bill Clinton, enero 1993). En la misma línea, en el proceso de discusión en las Naciones Unidas del tema de Iraq, Bush declaró que estaba dispuesto a tomar las acciones pertinentes porque las Naciones Unidas estaban habían dado señales de no estar a la altura de las circunstancias. Fue lo que retomó su secretario de estado Colin Powel cuando declaró que El Consejo de Seguridad de las Naciones Unidas no pasó la prueba en su incapacidad de unir posturas respaldadas por Estados Unidos para desarmar al presidente iraquí».

4. Discurso de Bush la noche del inicio de las hostilidades en Iraq.

5. Ignacio Ramonet no titubea en calificar de groseras mentiras de estado toda la parafernalia que montó el gobierno de Bush en los meses previos a la guerra en contra de Sadam Hussein. En la edición del mundo diplomático de julio 2003. "C'est l'histoire du voleur qui crie : « Au voleur ! »Comment pensez-vous que M. George W. Bush intitula le célèbre rapport d'accusation contre M. Saddam Hussein qu'il présenta le 12 septembre 2002 devant le Conseil de sécurité de l'ONU ? "Une décennie de mensonges et de défis ». Et qu'y affirmait-il en égrenant des " preuves » ? Un chapelet de mensonges ! L'Iraq, disait-il en substance, entretient des liens étroits avec le réseau terroriste Al-Qaida et menace la sécurité des Etats-Unis parce qu'il possède des " armes de destruction massive " (ADM) une expression terrifiante forgée par ses conseillers en communication». Ver Ignacio Ramonet, "Armes D'intoxication massive Mensonges d'Etat", Monde Diplomatique, Juillet 2003, p. 1. 
6. El gobierno de los Estados Unidos reconoció públicamente haber cometido un error en la justificación de la guerra a Iraq. «Después de todo lo que sabemos ahora, la alusión al intento iraquí de comprar uranio en África no debería haber formado parte del discurso de Bush sobre el estado de la nación».

7. Desde su llegada al poder el gobierno de George Bush ha demostrado varias actitudes alarmantes para los que defienden el multilateralismo en el trato de los asuntos internacionales. Así, Ignacio Ramonet hace el inventario de una serie de comportamientos de los halcones que rodean la administración del presidente de los Estados Unidos: Militan para que Washington se concentre sobre los lugares de poder en la hora de la globalización liberal: G7. FMI, OMC, Banco Mundial...Y quieren sustraer poco a poco a Estados Unidos al marco político multilateral. Por eso impulsaron al presidente Bush a que denunciara el protocolo de Kyoto sobre el efecto invernadero, el tratado ABM de misiles balísticos, el tratado que instaura una Corte Penal Internacional, el tratado sobre minas antipersonales, el protocolo de armas biológicas, el acuerdo sobre armas de pequeño calibre, el tratado sobre prohibición total de armas nucleares, y las convenciones de Ginebra sobre los prisioneros de guerra en lo que concierne a los detenidos en la cárcel de Guantánamo. El próximo paso sería la negativa del arbitraje del Consejo de seguridad. Lo cual amenazaría de muerte el sistema de las Naciones Unidas. Tomado en: http://www.monde-diplomatique.es/2003/03/ramonet.html

8. Ignacio Ramonet, presenta una de las motivaciones no declaradas que a su juicio pudo haber motivado la guerra de la Administración Bush en Ira. Una «motivación no confesada es el control del golfo árabe-pérsico y de sus recursos en hidrocarburos. Más de los dos tercios de las reservas mundiales de petróleo conocidas se encuentran concentradas bajo el suelo de algunos Estados situados en las orillas del Golfo: Irán, Iraq, Kuwait, Arabia saudita, Qatar y Emiratos Árabes Unidos. Para los países desarrollados, especialmente para Estados Unidos, que es un gran dilapidador de energía, esta región desempeña un papel capital y posee una de las claves fundamentales de su crecimiento y modo de vida. Toda intervención contra países del golfo se considera pues una amenaza para los "intereses vitales" de Estados Unidos. Desde 1980, en su discurso sobre el estado de la Unión, el presidente James Carter, premio Nobel de la paz 2002, definía la doctrina estadounidense para la región: "Todo intento por parte de cualquier potencia extranjera de tomar el control de la región del golfo Pérsico será considerado un ataque contra los intereses vitales de Estados Unidos de América. Y ese ataque será rechazado por todos los medios necesarios, incluida la fuerza militar". Ver RAMONET, I., "La era de la guerra perpetua», Mundo Diplomático, marzo 2003.

9. Los cuatro propósitos de las Naciones Unidas que reza el artículo 1 de la Carta de las Naciones Unidas son las siguientes: 1. Mantener la paz y la seguridad internacionales, y con tal fin: tomar medidas colectivas eficaces para prevenir y eliminar amenazas a la paz, y para suprimir actos de agresión u otros quebrantamientos de la paz; y lograr por medios pacíficos, y de conformidad con los principios de la justicia y del derecho internacional, el ajuste o arreglo de controversias o situaciones internacionales susceptibles de conducir a quebrantamientos de la paz;

2. Fomentar entre las naciones relaciones de amistad basadas en el respeto al principio de la igualdad de derechos y al de la libre determinación de los pueblos, y tomar otros medidas adecuadas para fortalecer la paz universal; 
3. Realizar la cooperación internacional en la solución de problemas internacionales de carácter económico, social, cultural o humanitario, y en el desarrollo y estímulo del respeto a los derechos humanos y a las libertades fundamentales de todos, sin hacer distinción por motivos de raza, sexo, idioma o religion; y

4. Servir de centro que armonice los esfuerzos de las naciones por alcanzar estos propósitos comunes

10. Especialmente el discurso en la escuela militar de West Point del primero de junio de 2002, en el que Bush declaró, entre otras cosas, que no estaba dispuesto a esperar nuevos ataques por parte de estados canallas y que su gobierno tenía el derecho de intervenir de manera preventiva para proteger la vida y los intereses de su país.

11. El artículo 51 de la Carta de las Naciones Unidas estipula que : «Ninguna disposición de esta Carta menoscabará el derecho inmanente de legítima defensa, individual o colectiva, en caso de ataque armado contra un Miembro de las Naciones Unidas, hasta tanto que el Consejo de Seguridad haya tomado las medidas necesarias para mantener la paz y la seguridad internacionales. Las medidas tomadas por los Miembros en ejercicio del derecho de legítima defensa serán comunicadas inmediatamente al Consejo de Seguridad, y no afectarán en manera alguna la autoridad y responsabilidad del Consejo conforme a la presente Carta para ejercer en cualquier momento la acción que estime necesaria con el fin de mantener o restablecer la paz y la seguridad internacionales». Artículo 51 de la Carta de las Naciones Unidas, firmada en San Francisco, el 26 de junio de 1945

12. Se podría citar entre los momentos difíciles que ha conocido la organización mundial a lo largo de su historia: el boicot de la Unión Soviética al aval de la ONU a la Guerra de Corea, la invasión de Francia y Gran Bretaña a Egipto sin la autorización de la ONU en 1956, y la Crisis de los Misiles en Cuba en 1962.

13. Aunque, para hablar propiamente habría que situar la conciencia mundial sobre el tema después del fin de la segunda guerra mundial, cuando el presidente estadounidense Woodrow Johnson propuso la creación de la Sociedad de Naciones. Decía al respecto en ese momento:

14. A este respecto, un documento publicado por el organismo internacional subraya: La fin de la guerre froide a indéniablemente donné au Conseil de sécutiré une place et un role que l'afforntement Est-Ouest ne lui avait pas permis de jouer autan que l'avaient voulu les fondateurs des Nations Unies. La multiplication des affaires dont il trite et des opértaciones de paix qu'il a mandatées depuis plus de dix ans en témoigne aisément».TEIXEIRA, P. Le conseil de sécurité á l'aube du XXI eme siecle,, UNIDIR, Institut des Nations Unies pour la recherche sur le désarmement, Genéve Suisse, 2002. P. 3.

15. SCHLESINGER, Arthur, La presidencia Imperial, Barcelona, Dopesa, 1974 pp. 19 y ss. Citado por PALOMARES LERMA, Gustavo,en, Teoría y concepto de las relaciones internacionales, Universidad Nacional de Educación a Distancia, Madrid, 1994, p. 182.

16. Discurso de Bush en la Casa Blanca el 15 de marzo de 2003.

17. Discurso de Bush en Washington, el 14 de septiembre de 2001. Tomado en internet en http://www.pce.es/SECINTERNACIONAL/estrat_segur_nacion.pdf

18. El secretario de Estados Unidos Colin Powel respondió a los que ven con suspicacia la acción de su gobierno en Iraq que en todo caso, ellos se sienten una policía necesaria debida a la justeza de la causa que defienden. 
19. Tomado del documento Estrategia de Seguridad Nacional de Bush, publicado por la Casa Blanca en septiembre de 2002.

20. Ibid.

21. Ibid.

22. Ibid.

23. Ibid.

24. El ministro francés de Asuntos exteriores, Dominique de Villepin, declaró que «Estamos convencidos, de que hace falta un mundo multipolar, y de que una potencia sola no puede asegurar el orden mundial". Ver, Le Journal du Dimanche, Paris, 16 de febrero de 2003.

25. George W. Bus, ha demostrado plena conciencia de ello cuando declara: A algunos les preocupa que hablar en términos de los que es justo o injusto puede no ser diplomático o puede ser descortés. Diferentes circustancias requieren métodos diferentes, pero no moralidades diferentes». Discurso de Bush en West Point, Nueva York, 1 de junio de 2002.

26. MORGENTHAU, H., La lucha por el poder y por la paz, Buenos Aires, GEL, 1986, p. 69. 